\title{
UKURAN DAN BENTUK LENGKUNG GIGI RAHANG BAWAH PADA SUKU MONGONDOW
}

\author{
${ }^{1}$ Rahmaya E. U. Paputungan \\ ${ }^{2}$ P. S. Anindita \\ ${ }^{2}$ Krista V. Siagian
}

\author{
${ }^{1}$ Kandidat SkripsiProgram Studi Pendidikan Dokter Gigi Fakultas Kedokteran \\ ${ }^{2}$ Program Studi Pendidikan Dokter GigiFakultas Kedokteran \\ Universitas Sam Ratulangi Manado \\ E-mail:inka.rep0993@gmail.com
}

\begin{abstract}
Mandibular arch size and form are required in order to establish proper diagnoses and orthodontic treatment plans. Mandibular dental arch is a factor affecting maximum stability of treatment outcomes. The purpose of this study was to determine means of mandibular arch size and form in Mongondow ethnic group.This research was classified into descriptive observational with cross sectional study. Sample of this research were 35 peoples aged 18-25 years at the original Mongondow ethnic group based on two generation of grandparents. Samples were taken by using purposive sampling method. The measurement of dental arch length and width were done in sagittal and transversal direction based on the Raberin's method. Results showed that the average values of mandibular arch length in Mongondow ethnic group which categorized as depths of canines (L31), depths first molars (L61) and depths of second molars were $5.18 \mathrm{~mm} ; 24.26 \mathrm{~mm}$; and $39.34 \mathrm{~mm}$ respectively. The average values of mandibular arch width which categorized as inter canines (L33), inter first molars (L66) and inter second molars (L77) were $27.38 \mathrm{~mm}, 45.60 \mathrm{~mm}$ and $53.59 \mathrm{~mm}$ respectively. The most mandibular arch form of Mongondow ethnic group was mid (51.4\%) and the less of this group was pointed (5.7\%).
\end{abstract}

Keywords: dental arch size, dental arch form, mandibular, Mongondow ethnic group

\begin{abstract}
Abstrak: Ukuran dan bentuk lengkung gigi rahang bawah sangat diperlukan dalam menentukan diagnosa dan rencana perawatan ortodontik yang tepat. Lengkung gigi rahang bawah merupakan faktor yang sangat berpengaruh dalam mempertahankan stabilitas hasil perawatan ortodonti. Tujuan penelitian ini yaitu untuk mendapatkan rerata ukuran dan bentuk lengkung gigi rahang bawah pada suku Mongondow. Jenis penelitian ini yaitu observasional deskriptif dengan desain penelitian cross sectional study. Sampel yang diperoleh sebanyak 35 orang suku Mongondow asli dari dua generasi yag berusia 18-25 tahun. Pengambilan sampel dilakukan dengan menggunakan teknik purposive sampling. Pengukuran panjang dan lebar lengkung gigi diukur dalam arah sagital dan transversal pada model studi/hasil cetakan rahang bawah dengan metode Raberin. Hasil pengukuran diperoleh rerata ukuran panjang lengkung gigi rahang bawah pada suku Mongondow yang dikategorikan sebagai kedalaman kaninus (L31), kedalaman molar pertama (L61) dan kedalaman molar kedua (L71) berturut-turut yaitu 5,18 mm; 24,26 mm; dan 39,34 mm. Rerata ukuran lebar lengkung gigi yang dikategorikan sebagai lebar interkaninus (L33), lebar intermolar pertama (L66) dan lebar intermolar kedua (L77) berturut-turut yaitu 27,38 mm; 45,60 mm dan; 53,59 mm. Bentuk lengkung gigi rahang bawah pada suku Mongondow paling banyak yaitu bentuk mid $(51,4 \%)$ dan yang paling sedikit yaitu bentuk pointed (5,7\%).
\end{abstract}

Kata kunci: ukuran lengkung gigi, bentuk lengkung gigi, rahang bawah, suku Mongondow 
Diagnosis merupakan suatu langkah yang harus dilakukan sebelum merencanakan suatu perawatan. ${ }^{1}$ Diagnosis di bidang Ortodonsia dapat didefinisikan sebagai suatu studi dan interpretasi data klinis untuk menetapkan ada tidaknya anomali (maloklusi). ${ }^{1}$ Ukuran dan bentuk lengkung gigi sangat berpengaruh dalam diagnosis dan penentuan rencana perawatan kasus ortodontik, estetik serta stabilisasi dari gigigeligi. $^{2}$ Raberin menyatakan bahwa salah satu syarat utama dalam menentukan diagnosis dan rencana perawatan ortopedi dentofasial yaitu susunan gigi pada lengkung rahang bawah, karena lengkung gigi rahang bawah merupakan faktor yang sangat berpengaruh dalam mempertahankan stabilitas hasil perawatan ortodontik. ${ }^{2}$

Bentuk lengkung gigi menjadi pertimbangan utama bagi peran klinis, khususnya dalam memperkirakan perubahan pertumbuhan yang akan datang dan hasil perawatan, mengingat bahwa estetik yang baik adalah bila terjadi harmonisasi antara lengkung gigi dan morfologi ukuran gigi-geligi. ${ }^{3}$ Penelitian mengenai ukuran dan bentuk lengkung gigi telah dimulai sejak awal berkembangnya ilmu ortodontik itu sendiri. ${ }^{4}$ Berbagai metode dan formulasi dikembangkan untuk dapat memprediksi bentuk lengkung gigi individual, tetapi belum ada di antara formulasi tersebut yang dapat mewakili variasi bentuk lengkung gigi pada seluruh populasi dan ras. ${ }^{4}$

Sassouni dan Rickets berpendapat bahwa kelompok ras yang berbeda akan menampilkan pola kraniofasial yang berbeda pula. ${ }^{5}$ Indonesia merupakan salah satu negara kepulauan yang terbesar di dunia yang mempunyai beberapa kelompok etnik suku bangsa, dengan demikian nilai normal ukuran dan bentuk lengkung gigi khususnya rahang bawah pada ras kaukasoid belum tentu merupakan bentuk lengkung gigi normal bagi ras yang lain. Oleh karena itu, perlu dilakukan penelitian nilai normal ukuran dan bentuk lengkung gigi rahang bawah pada masing-masing ras, khususnya untuk bangsa Indonesia. ${ }^{6}$

Sulawesi Utara merupakan salah satu provinsi di Indonesia yang memiliki beberapa suku, salah satunya suku Mongondow. Berdasarkan hal tersebut, penulis merasa perlu untuk melakukan penelitian tentang ukuran dan bentuk lengkung gigi rahang bawah pada suku Mongondow dengan metode Raberin sebagaipendukung penelitian-penelitian terdahulu.

\section{METODE PENELITIAN}

Jenis penelitian ini observasional deskriptif dengan desain penelitian potong lintang. Penelitian ini dilaksanakan di Kelurahan Matali Kota Kotamobagu. Waktu penelitian telah dilaksanakan pada bulan Juni - Juli tahun 2015.Populasi pada penelitian ini yaitu suku Mongondow di Kelurahan Matali Kotamobagu yang merupakan keturunaan suku Mongondow asli dari dua generasi yang berusia 18-25 tahun.

Pemilihan sampel dilakukan dengan menggunakan teknik purposive sampling dimana sampel yang diambil ditentukan berdasarkan kriteria yang ditentukan. Besar sampel yang diperoleh sebanyak 35 orang yang dihitung dengan menggunakan rumus besar sampel deskriptif kategorik:

Keterangan:

$$
\mathrm{n}=\frac{\mathrm{Z} \alpha^{2} \mathrm{pq}}{\mathrm{d}^{2}}
$$

$\mathrm{n} \quad=$ besar sampel

$\mathrm{Z} \alpha=$ standar deviasi normal $=95 \%=1,96$

$\mathrm{p}=$ prakiraan proporsi populasi $=10 \%=0,1$

$\mathrm{q} \quad=1-\mathrm{p}=0,9$

$\mathrm{d}=$ penyimpangan terhadap populasi $=10 \%=0,1$

Pengukuran panjang dan lebar lengkung gigi rahang bawah pada suku Mongondow dilakukan pada hasil cetakan / model studi dengan menggunakan metode Raberin. Alat ukur yang digunakan yaitu Vernier caliper dengan ketelitian 0,05 mm. Panjang lengkung gigi diukur dalam arah sagital yang dikategorikan sebagai kedalaman kaninus (L31), kedalaman molar pertama (L61) dan kedalaman molar kedua (L71), dimana diukur jarak dari pertengahan gigi insisivus sentralis tegak lurus terhadap garis yang menghubungkan 
puncak tonjol kaninus (L31), jarak dari pertengahan gigi insisivus sentralis tegak lurus terhadap garis yang menghubungkan tonjol mesio-bukal gigi molar pertama permanen kiri dan kanan (L61) dan jarak dari pertengahan gigi insisivus sentralis tegak lurus terhadap garis yang menghubungkan tonjol disto-bukal gigi molar pertama permanen kiri dan kanan (L71) (Gambar 1). ${ }^{2}$

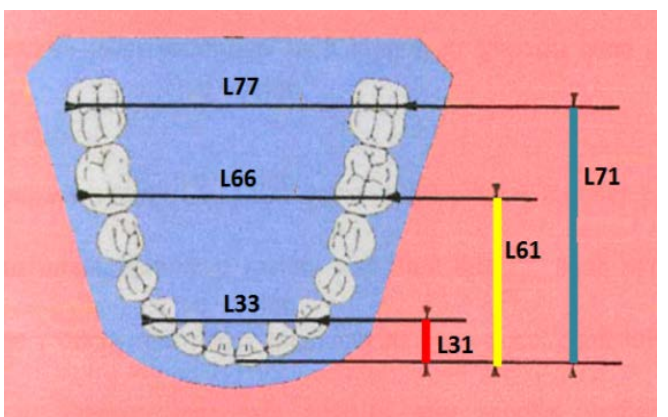

Gambar 1. Metode pengukuran panjang lengkung gigi rahang bawahmenurut Raberin ${ }^{2}$

Pengukuran lebar lengkung gigi dikategorikan sebagai lebar interkaninus (L33), lebar intermolar petama (L66) dan lebar intermolar kedua (L77) dimana diukur jarak antara puncak tonjol kaninus kiri dan kanan (L33), puncak tonjol mesiobukal molar pertama permanen kiri dan kanan (L66), serta puncak tonjol distobukal molar kedua permanen kiri dan kanan (L77).

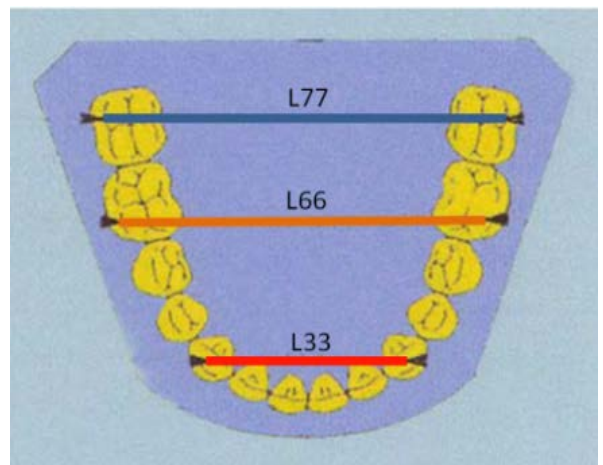

Gambar 2. Pengukuran lebar lengkung gigi menurut Raberin ${ }^{2}$

Setelah dilakukan pengukuran pada lengkung gigi, ditentukan bentuk lengkung gigi (Gambar 3) berdasarkan persentase deviasi relatif dari perbandingan L31/L33, L61/L66, L71/L77, L33/L66 dan L61/L71 dengan klasifikasi sebagai berikut:

a. Narrow (sempit) bila nilai persentase deviasi relatif dari perbandingan L31/L33, L61/L66 dan L71/L77 hasilnya positif $(+)$.

b. Wide (lebar) bila nilai persentase deviasi relatif dari perbandingan L31/L33， L61/L66 dan L71/L77 hasilnya negatif (-).

c. Mid (sedang) bila nilai persentase deviasi relatif dari kelima perbandingan di atas hasilnya tidak ada perbandingan yang signifikan.

d. Pointed (runcing/tajam) bila nilai persentase deviasi relatif dari perbandingan L31/L33 jauh lebih besar dari perbandingan lainnya (L61/L66, L71/L77, L33/L66 dan L61/L71).

e. Flat (datar) bila nilai persentase deviasi relatif dari perbandingan L31/L33 jauh lebih kecil dari perbandingan lainnya (L61/L66, L71/L77, L33/L66 dan L61/L71).

Nilai deviasi relatif dihitung dengan mengurangkann nilai yang diukur terhadap rata-rata seluruh sampel yang diukur.

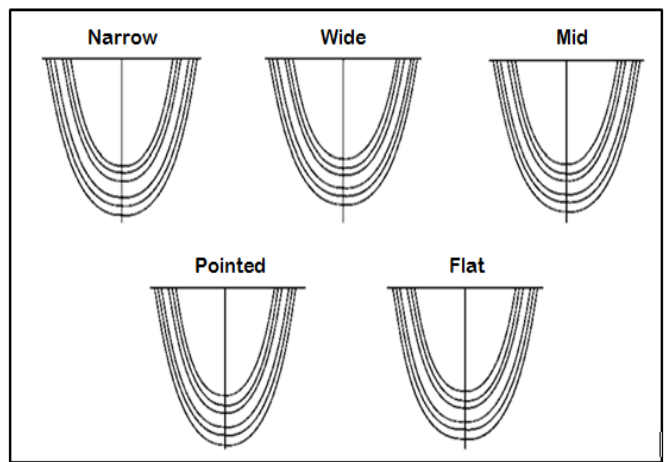

Gambar 3. Klasifikasi bentuk lengkung gigi menurut Raberin ${ }^{2}$

Analisis data pada penelitian ini yaitu yaitu dengan menghitung rerata dan standar deviasi ukuran lengkung gigi seluruh sampel, menentukan bentuk lengkung gigi rahang bawah seluruh sampel dan menghitung persentase dari masing-masing 
bentuk lengkung gigi rahang bawah tersebut.

\section{HASIL PENELITIAN}

Tabel 1 memperlihatkan distribusi dari 30 responden berdasarkan jenis kelamin. Responden perempuan lebih banyak $(68,57 \%)$ dari responden laki-laki $(31,43 \%)$.

Tabel 1. Distribusi karakteristik responden berdasarkan jenis kelamin

\begin{tabular}{ccc}
\hline Jenis Kelamin & $\mathrm{n}$ & $\%$ \\
\hline Laki-laki & 11 & 31,43 \\
Perempuan & 24 & 68,57 \\
Jumlah & 35 & 100 \\
\hline
\end{tabular}

Tabel 2 menunjukkan karakteristik responden berdasarkan usia yang memiliki jumlah paling banyak yaitu responden yang berusia 18 tahun dengan jumlah 10 orang $(28,57 \%)$ dan yang paling sedikit yaitu reponden yang berusia 22 tahun dengan jumlah 2 orang (5,71\%).

Tabel 2. Distribusi karakteristik responden berdasarkan usia

\begin{tabular}{ccc}
\hline Usia (Tahun) & $\mathrm{n}$ & $\%$ \\
\hline 18 & 10 & 28,57 \\
19 & 5 & 14,29 \\
20 & 4 & 11,43 \\
21 & 4 & 11,43 \\
22 & 2 & 5,71 \\
23 & 3 & 8,57 \\
24 & 4 & 11,43 \\
25 & 3 & 8,57 \\
Jumlah & 35 & 100 \\
\hline
\end{tabular}

Berdasarkan pengukuran yang dilakukan terhadap sampel, dapat dilihat rerata ukuran lengkung gigi rahang bawah suku Mongondow yang diukur dalam arah sagital dan transversal. Tabel 3 menunjukkan bahwa hasil rerata pengukuran panjang lengkung gigi rahang bawah yang diukur dalam arah sagital (L31, L61 dan L71)) berturut-turut yaitu, 5,18 mm; 24,26 mm dan 39,34 mm. Rerata pengukuran lebar lengkung gigi diukur dalam arah transversal (L33, L66 dan L77) berturut-turut yaitu 27,38 mm, 45,60 mm dan 53,59 mm.

Tabel 3. Rerata ukuran lengkung gigi rahang bawah pada suku Mongondow

\begin{tabular}{crc}
\hline Pengukuran & \multicolumn{1}{c}{$\begin{array}{c}\text { Rerata } \\
(\mathrm{mm})\end{array}$} & $\begin{array}{c}\text { Standar Deviasi } \\
(\mathrm{mm})\end{array}$ \\
\hline Sagital & & \\
L31 & 5,18 & 1,20 \\
L61 & 24,26 & 2,97 \\
L71 & 39,34 & 3,21 \\
Transversal & & \\
L33 & 27,38 & 2,82 \\
L66 & 45,60 & 2,92 \\
L77 & 53,59 & 3,59 \\
\hline
\end{tabular}

Tabel 4. menunjukkan bahwa bentuk lengkung gigi rahang bawah suku Mongondow dengan persentase paling besar yaitu bentuk mid (51,4\%) dan bentuk lengkung gigi dengan persentase terkecil yaitu bentuk pointed (5,7\%).

Tabel 4. Distribusi bentuk lengkung gigi rahang bawah pada suku Mongondow

\begin{tabular}{ccc}
\hline Bentuk & $\mathrm{n}$ & $(\%)$ \\
\hline Narrow & 9 & 25,7 \\
Wide & 3 & 8,6 \\
Mid & 16 & 51,4 \\
Pointed & 2 & 5,7 \\
Flat & 3 & 8,6 \\
Jumlah & 35 & 100 \\
\hline
\end{tabular}

\section{BAHASAN}

Hasil pengukuran panjang lengkung gigi rahang bawah secara sagital pada suku Mongondow yang dikategorikan sebagai L31, L61 dan L71 (Tabel 3) tidak jauh berbeda dengan hasil penelitian Jesika tahun 2012 pada mahasiswa suku Batak Fakultas Kedokteran Gigi (FKG) dan Fakultas Teknik (FT) Universitas Sumatera Utara (USU) dimana terdapat perbedaan yang variatif dan kurang dari $1 \mathrm{~mm}$. Nilai rerata L31 dan L61 pada suku Mongondow sedikit lebih besar daripada mahasiswa suku Batak FKG dan FT USU, sedangkan L71 sedikit lebih kecil. ${ }^{7} \mathrm{Hal}$ ini menunjukkan bahwa pada suku Mongondow, pertumbuhan lengkung gigi 
dalam arah anterior lebih besar / ke depan (protrusif) namun dalam arah posterior lebih kecil dibandingkan dengan mahasiswa FKG dan FT USU suku Batak.

Hasil pengukuran lebar lengkung gigi rahang bawah secara transversal yang dikategorikan sebagai L33, L66 dan L77 pada suku Mongondow (Tabel 3) terdapat perbedaan yang variatif dengan penelitian pada mahasiswa suku Batak FKG dan FT USU, dimana nilai rerata L33 pada suku Mongondow sedikit lebih kecil dari mahasiswa suku Batak FKG dan FT USU dengan selisih kurang dari $1 \mathrm{~mm}$, sedangkan nilai rerata L66 dan L77 pada suku Mongondow sedikit lebih besar daripada mahasiswa suku Batak FKG dan FT USU dengan selisih lebih dari $1 \mathrm{~mm}^{7}$ Dari hasil tersebut, dapat dikatakan bahwa ukuran lengkung gigi dalam arah posterior pada mahasiswa FKG dan FT USU suku Batak sedikit lebih lebar dari suku Mongondow.

Penelitian Hasibuan tahun 2009 terhadap lengkung gigi rahang bawah ras Deutro-Melayu yaitu suku Melayu, Aceh (kecuali Gayo), Jawa, Minangkabau, Bali, Sunda, Palembang dan Makassar di FKGUSU, diperoleh ukuran rata-rata L33, L66 dan L77 lebih kecil daripada suku Mongondow yang juga merupakan ras Deutro-Melayu. ${ }^{8}$ Hal ini menunjukkan bahwa meskipun masih dalam satu rumpun, namun masih terdapat perbedaan yang dapat disebabkan oleh faktor genetik maupun lingkungan. ${ }^{9}$

Berdasarkan lima klasifikasi bentuk lengkung gigi rahang bawah menurut Raberin, maka dari 35 sampel rahang bawah pada suku Mongondow dijumpai memiliki kelima klasifikasi bentuk lengkung gigi tersebut. Bentuk lengkung gigi rahang bawah pada suku Mongondow (Tabel 4) yang paling banyak yaitu bentuk mid (51,4\%). Bentuk lengkung gigi pada suku Mongondow paling sedikit yaitu pointed(5,7\%). Bentuk mid diperoleh karena adanya keseimbangan ukuran lengkung gigi dalam arah anteroposterior dan lateral. Lain halnya dengan bentuk pointed yang diperoleh karena ukuran lengkung gigi dalam arah anteroposterior lebih besar dibandingkan arah lateral.

Bentuk lengkung gigi menjadi pertimbangan utama bagi para dokter gigi, khususnya dalam memperkirakan perubahan pertumbuhan yang akan datang dan stabilisasi hasil perawatan. Para ortodontis terdahulu menetapkan satu bentuk lengkung gigi yang ideal sebagai hasil dari perawatan ortodontik, namun Raberin dalam penelitiannya menyatakan bahwa bentuk lengkung gigi rahang bawah yang ideal tidak hanya satu bentuk, karena bentuk lengkung yang ideal pada satu individu tidak sama dengan individu yang lain. ${ }^{2,10}$

Ukuran dan bentuk lengkung gigi pada suatu individu tidak dapat dibedakan berdasarkan suku karena tidak terdapat perbedaan yang menonjol pada suku-suku di Indonesia. Untuk itu, dapat diindikasikan bahwa dalam melakukan rencana perawatan khususnya di bidang Ortodonsia harus benar-benar dipertimbangkan bentuk lengkung gigi pasien karena setiap individu memiliki bentuk lengkung gigi yang berbeda-beda. Jika pemilihan bentuk archwire dilakukan dengan tepat, maka stabilitas hasil perawatan akan maksimal.

\section{SIMPULAN}

Berdasarkan hasil penelitian dapat disimpulkan bahwa rerata ukuran panjang lengkung gigi rahang bawah yang diukur dalam arah sagital yang dikategorikan sebagai L31, L61 dan L71 berturut-turut yaitu 5,18 mm, 24,26 mm dan 39,34 mm. Rerata ukuran lebar lengkung gigi rahang bawah yang diukur dalam arah transversal yang dikategorikan sebagai L33, L66 dan L77 berturut-turut yaitu 27,38 mm,45,60 $\mathrm{mm}$, dan 53,59 mm. Bentuk lengkung gigi rahang bawah pada suku Mongondow yang paling banyak yaitu middan yang paling sedikit yaitu pointed.

\section{SARAN}

1. Perlu dilakukan penelitian lebih lanjut dengan jumlah sampel yang lebih besar agar didapatkan validitas yang lebih tinggi. 
2. Untuk menunjang keberhasilan hasil perawatan kesehatan gigi dan mulut khususnya di bidang Ortodonsia, disarankan bagi para praktisi/dokter gigi agar lebih memperhatikan penentuan ukuran dan bentuk lengkung gigi mengingat setiap individu memiliki ukuran dan bentuk lengkung gigi yang berbeda-beda.

\section{DAFTAR PUSTAKA}

1. Rahardjo P. Diagnosis ortodonti. Edisi 1. Surabaya: Airlangga University Press; 2008. h.1-2.

2. Raberin M, Laumon B, Martin JL, Brunner F. Dimension and form of dental arches in with normal occlusion. Am J Orthod and Dentofac Orthod. 1993; 104: 67-72.

3. Desi FK, Sylvia M, Kristiani S. Hubungan lebar mesiodistal gigi insisif dengan lengkung gigi pada kasus berdesakan anterior. Jurnal PDGI. 2007; 50(2): 52-5.

4. White LW. Individualized ideal arches. J Clin Orthod. 1978; 12(11): 779-87.

5. Febrina RS, Eky SSS, Endah M. Ukuran dan bentuk lengkung gigi rahang bawah pada mahasiswa fakultas kedokteran gigi Unpad. J Ked Gigi. 1997; 9: 22-7.

6. Mieke SMAR. Variasi normal ukuran gigi, rahang dan wajah penduduk pulau flores dan timor nusa tenggara timur. Makalah Ilmiah Kedokteran Gigi FKG Usakti. 1993; 2: 460-7.

7. Jesika. Ukuran dan bentuk lengkung gigi rahang bawah pada mahasiswa suku batak fakultas kedokteran gigi dan teknik universitas Sumatera Utara. [Skripsi] Medan. Universitas Sumatera Utara. 2012: h.21-4.

8. Hasibuan MK. Ukuran dan bentuk lengkung gigi rahang bawah pada mahasiswa FKG-USU ras deutromelayu. [Skripsi] Medan. Universitas Sumatera Utara. 2009: h.6, 24.

9. Cassidy KM, Edward F, Elizabeth A, Robert G. Genetic influence on dental arch form. J Angle Orthod. 1998; 68(5): 445-9.

10.Olmez S, Dogan S. Comparison of the arch form and dimensions in various malocclusions of the Turkish population. Open Journal of Stomatology. 2011; 1: 158-164. 